Conferencias, seminarios y trabajos de Matemática

ISSN: 1515.4904

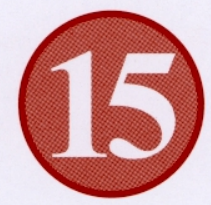

Workshop on

Mathematical

Modelling of Energy

and Mass Transfer

Processes, and

Applications

Domingo A. Tarzia

Rodolfo H. Mascheroni (Eds.) 


\title{
SIMPLE, PRACTICAL, AND EFFICIENT ON-LINE CORRECTION OF PROCESS DEVIATIONS IN BATCH RETORT THROUGH SIMULATION
}

\author{
SIMPSON, R. ${ }^{1}$, FIGUEROA, I. ${ }^{1}$, and TEIXEIRA, A. ${ }^{2}$
}

1 Departamento de Procesos Químicos, Biotecnológicos, y Ambientales; Universidad Técnica Federico Santa María; P.O. Box 110-V; Valparaíso, Chile.

Phone: 56-32-2654302; Fax: 56-32-2654478

E-mail: ricardo.simpson@usm.cl

2 Department of Agricultural and Biological Engineering; 207 Frazier Rogers Hall, P. O. Box 110570; University of Florida, Gainesville, FL 32611-0570, USA.

\begin{abstract}
This paper describes a practical and efficient (nearly precise, yet safe) strategy for on-line correction of thermal process deviations during retort sterilization of canned foods. Commercial systems currently in use for on-line correction of process deviations do so by extending process time to that which would be needed had the entire process been carried out at the lower retort temperature reached at the lowest point in the deviation ("commercial" correction). This method of correction often results in extensive unnecessary over-processing with concomitant deterioration in product quality, and costly interruption to the retort loading/unloading rotation schedules in retort cook room operations. These problems are addressed by a novel control strategy that takes into account the duration of the deviation in addition to the magnitude of the temperature drop. It calculates a "proportional" extended process time at the recovered retort temperature that will deliver the final specified target lethality with very little over processing in comparison to current industry practice. In addition, a strategy for online-correction without extending process time was developed and preliminarily validated. Results from an exhaustive "optimization" search routine using the complex method are also reported, that show the proposed strategy will always result in a corrected process that delivers no less than the final target lethality specified for the originally scheduled process.
\end{abstract}

KEY WORDS: On-line Control, Low Acid Foods, Batch Retort, Process Deviations.

\section{INTRODUCTION}

Thermal processing is an important method of food preservation in the manufacture of shelf stable canned foods. Most of the work done in thermal processes deal with the microbiological and biochemical aspects of the process and are rarely related to the engineering aspects or practical industrial operations of the process. The basic function of a thermal process is to inactivate pathogenic and food spoilage causing bacteria in sealed containers of food using heat treatments at temperatures well above ambient boiling point of water in pressurized steam retorts (autoclaves). Excessive heat treatment should be avoided because it is detrimental to food quality, wastes energy, and under utilizes plant capacity. Thermal process calculations, in which process times at specified retort temperatures are calculated in order to achieve safe levels of microbial inactivation (lethality), must be carried out carefully to assure public health safety (Bigelow and others, 1920; Ball, 1928; Stumbo, 1973; Pham, 1987; Teixeira, 1992; Holdsworth, 1997). However, over-processing must be avoided thermal processes also have a detrimental effect on the quality (nutritional and sensorial 
factors) of foods. Therefore, the accuracy of the methods used for this purpose is of importance to food science and engineering professionals working in this field.

Control of thermal process operations in food canning factories has consisted of maintaining specified operating conditions that have been predetermined from product and process heat penetration tests, such as the process calculations for the time and temperature of a batch cook. Sometimes unexpected changes can occur during the course of the process operation such that the pre-specified processing conditions are no longer valid or appropriate. These types of situations are known as process deviations. Because of the important emphasis placed on the public safety of canned foods, processors must operate in strict compliance with the US Food and Drug Administration's Low-Acid Canned Food (FDA/LACF) regulations. A succinct summary and brief discussion of these regulations can be found in Teixeira (1992). Among other things, these regulations require strict documentation and record-keeping of all critical control points in the processing of each retort load or batch of canned product. Particular emphasis is placed on product batches that experience an unscheduled process deviation, such as when a drop in retort temperature occurs during the course of the process, which may result from loss of steam pressure. In such a case, the product will not have received the established scheduled process, and must be either fully reprocessed, destroyed, or set aside for evaluation by a competent processing authority. If the product is judged to be safe then batch records must contain documentation showing how that judgment was reached. If judged unsafe, then the product must be fully reprocessed or destroyed. Such practices are costly.

In one very traditional method, on-line correction is accomplished by extending process time to that which would be needed had the entire process been carried out at the retort temperature reached at the lowest point in the deviation (Larkin, 2002). This method of correction will always assure sufficient food safety (process lethality), but often results in significant unnecessary overprocessing with concomitant deterioration in product quality. Alternative methods proposed initially by Teixeira and Manson (1982) and Datta, Teixeira and Manson (1986), and later summarized in Teixeira and Tucker (1997) and demonstrated and validated by Teixeira, Balaban, Germer, Sadahira, Teixeira-Neto, and Vitali (1999) make use of heat transfer simulation software to automatically extend process time at the recovered retort temperature to reach precisely the original target lethality required of the process. An alternative approach to on-line correction of process deviations was described in the work of Akterian $(1996,1999)$, who calculated correction factors using mathematical sensitivity functions.

The aim of this research study was the development of a safe, simple, efficient and easy to use procedure to manage on-line corrections of unexpected process deviations in any canning plant facility. Specific objectives were to:

1. Develop strategy to correct the process deviation by an alternative "proportionalcorrected" process that delivers no less than final target lethality, but with near minimum extended process time at the recovered retort temperature.

2. Demonstrate strategy performance by comparing "proportional-corrected" with "commercial-corrected" and "exact-corrected” process times.

3. Demonstrate consistent safety of the strategy by exhaustive search over an extensive domain of product and process conditions to find a case in which safety is compromised. 
4. Develop and preliminarily validate a strategy for online-correction without extending process time for any low acid canned food.

\section{METHODOLOGY}

\section{Scope of Work}

To reach the objectives stated above, the approach to this work was carried out in four tasks, one in support of each objective. Task 1 consisted of developing the strategy for on-line correction of process deviations with minimum extended process time using the method of "proportional correction". Task 2 consisted of choosing appropriate mathematical heat transfer models for construction of the equivalent lethality curves or "look-up tables" needed for use with each respective strategy, and for determining the final lethality and quality retention for each of the thousands of cases simulated in the study. Task 3 included the complex optimization search routine that was carried out to demonstrate validity and consistent safety of the strategy. Task 4 consisted of developing and validating the strategy for on-line correction of process deviations without extending process time.

Methodology employed in carrying out each of these tasks is described in greater detail below.

\section{Task 1 - Proportional Correction Strategy Development}

The objective for the strategy required in this task was to accomplish an on-line correction of an unexpected retort temperature deviation by an alternative process that delivers final target lethality, but with minimum extended process time at the recovered retort temperature. This would be accomplished with use of the same alternative process "look-up tables" that would normally be used with currently accepted methods of on-line correction of process deviations, but with a "proportional correction" applied to the alternative process time that would reduce it to a minimum without compromising safety. In order to fully understand this strategy, it will be helpful to first review the currently accepted method that is in common practice throughout the industry. Commercial systems currently in use for on-line correction of process deviations do so by extending process time to that which would be needed to deliver the same final lethality had the entire process been carried out with an alternative lower constant retort temperature equal to that reached at the lowest point in the deviation. These alternative retort temperature-time combinations that deliver the same final process lethality $\left(F_{o}\right)$ are called equivalent lethality processes. When these equivalent time-temperature combinations are plotted on a graph of process time versus retort temperature, they fall along a smooth curve called an equivalent lethality curve. These curves are predetermined for each product from heat penetration tests and thermal process calculations carried out for different retort temperatures.

The strategy will calculate the corrected process time $\left(t_{D}\right)$ as a function of the temperature drop experienced during the deviation, but also the time duration of the deviation. The following expression illustrates mathematically how this "proportional-corrected" process time would be calculated for any number (n) of deviations occurring throughout the course of a single process:

$t_{D}=t_{T R T}+\sum_{i=1}^{n}\left(t_{D}-t_{T R T}\right)\left(\frac{\Delta t_{i}}{t_{T R T}}\right), t_{D} \geq t_{T R T}$

If we considered the commercial correction as a valid correction, that is:

$t_{D \text { commercial }}=t_{T R T}+\left(t_{D}-t_{T R T}\right) \frac{t_{T R T i}}{t_{T R T}}$ 
then it is intuitive that a safe correction for a process deviated for a short time is a correction proportional to the time the deviation occurs:

$t_{D \text { proportional }}=t_{T R T}+\left(t_{D}-t_{T R T}\right) \frac{\Delta t_{i}}{t_{T R T}}$

\section{Task 2 - Performance Demonstration}

This task consisted of demonstrating the performance of these strategies by simulating the occurrence of process deviations happening at different times during the process (early, late and randomly) to both solid and liquid canned food products, calculating the alternative corrected process times, and predicting the outcomes of each corrected process in terms of final lethality and quality retention. For each deviation, three different alternative corrected process times were calculated:

- "Exact correction”, giving corrected process time to reach precisely the final target lethality specified for the scheduled process, using computer simulation with heat transfer models;

- "Proportional-correction”, using the strategy described in this paper with look-up tables; and,

- “Commercial correction”, using current industry practice with look-up tables (manually or computerized).

The heat transfer models were explicitly chosen to simulate the two extreme heat transfer cases encountered in thermal processing of canned foods. The rationale behind this decision was that canned foods possess heating characteristics between these two extreme situations. Conclusions extracted from these simulations will be extended to all canned foods.

The $\mathrm{F}$ value is calculated by:

$F=\int_{0}^{t} 10 \frac{T_{c p}(t)-T_{r e f}}{z} d t$

First was the case of pure conduction heating of a solid product under a still-cook retort process (equation 5 is the differential equation for heat conduction, Biot $>40$ ). The second was the case of forced convection heating of a liquid product under mechanical agitation (equation 6 is the differential equation for heat convection, Biot $<1$ ). In both cases, the container shape of a finite cylinder was assumed, typical of a metal can or wide-mouthed glass jar. However, suitable models appropriate for a true container shapes can be used as required for this purpose. Examples of such models can be found in the literature (Teixeira and others, 1969; Manson and others, 1970; Manson and others, 1974; Datta and others, 1986; Simpson and others, 1989; Simpson and others, 2004). The product and process conditions chosen to carry out the demonstrated simulations for each case are given in Table 1.

$$
\begin{aligned}
& \frac{\partial T}{\partial t}=\alpha\left[\frac{1}{r} \frac{\partial}{\partial r}\left(r \frac{\partial T}{\partial r}\right)+\frac{\partial^{2} T}{\partial h^{2}}\right] \\
& \frac{\partial T(t)}{\partial t}=\frac{U_{h t} \cdot A}{\rho \cdot V o l \cdot C p}\left[T R T \_\operatorname{corr}(t)-T(t)\right]
\end{aligned}
$$

\section{Task 3 - Demonstration of Safety Assurance by Complex Optimization Search Routine}

This on-line correction strategy was validated and tested for safety assurance by executing a strict and exhaustive search routine with the use of the heat transfer models selected in Task 2 on high-speed computer. The problem to be solved by the search routine was to determine if the 
minimum final lethality delivered by all the corrected processes that could be found among all the various types of deviations and process conditions considered in the problem domain met the criterion that it had to be greater than or equal to the lethality specified for the original scheduled process. This criterion can be expressed mathematically:

$$
\underset{U}{\operatorname{Min}}\left\lfloor F_{\text {proportion al }}-F_{\text {Tol }}\right\rfloor \geq 0
$$

Table 2 identifies the various types of deviations and process conditions that were explored and evaluated in the search routine (problem domain). The search routine was designed as an attempt to find a set of conditions under which the required search constraint was not met. The table gives the symbol used to represent each variable and a description of that variable, along with the minimum and maximum values limiting the range over which the search was conducted.

\section{Task 4 - On-line Correction without Extending Process Time}

For the developing of this strategy, we assume the retort control system to include a computer that is running the software containing the appropriate mathematical heat transfer model, and it reads the actual retort temperature from a temperature-sensing probe through an analogue/digital (A/D) data acquisition system. This continual reading of retort temperature would be used as real-time input of dynamic boundary condition for the mathematical heat transfer model. The model, in turn, would be accurately predicting the internal product cold spot temperature profile as it develops in response to the actual dynamic boundary condition (retort temperature). As the predicted cold spot temperature profile develops over time, the accumulating lethality $\left(F_{0}\right)$ would be calculated by the General method, and would be known at any time during the process. Should a deviation occur during the process a simulated search routine would be carried out on the computer to find the combination of process conditions for the remainder of the process that would result in meeting the final target lethality without over extending process time. The key in this strategy was to identify the retort temperature as the control variable to be manipulated during the remainder of the process (rather than process time). Therefore, upon recovery of the deviation, the search routine would find the new higher retort temperature to be used for the remainder of the process, and send the appropriate signals through the data acquisition system to readjust the retort temperature accordingly.

Increasing retort temperature cannot be accomplished without increasing steam pressure correspondingly, which dictates a practical upper limit to choice of higher retort temperature. This upper limit comes into play when the deviation occurs near the end of the process, when the little time remaining forces the simulation search routine to choose the upper limit for retort temperature. In these cases, the safety requirement for reaching the final target lethality $\left(F_{0}\right)$ must take priority over compromising process time. This will inevitably require some extension in process time, but it will be an absolute minimum, that would not likely upset scheduling routines. Validation of this method was confirmed by demonstrating consistent safety of the strategy by exhaustive "optimization" search over an extensive domain of product and process conditions in an attempt to find a case in which safety was compromised. No such case could be found.

This control strategy finds the lowest process temperature, $\mathrm{TRT}_{\mathrm{H}}$, at which must be reestablishing the process temperature after the deviation i for the rest of the processing time, so the original process time remains the same and the required lethality value $\left(\mathrm{F}_{\mathrm{obj}}\right)$ is reached. 
$T R T_{H}=\operatorname{Min}\left\{\operatorname{TRT} / F_{p} \geq F_{o b j} \wedge t_{p}{ }^{\prime}=t_{p}\right\}$

If $\mathrm{TRT}_{\mathrm{H}}$ surpasses the practical limits, the final target lethality $\left(\mathrm{F}_{\mathrm{o}}\right)$ is more important that the process time, that must be extended according to:

If $T R T_{H}>T R T_{\max } \Rightarrow T R T_{H}=T R T_{\max } \wedge t_{p}{ }^{\prime}=\operatorname{Min}\left\{t_{p} / F_{p} \geq F_{o b j}\right\}$

For a process that experiments more than one deviation, the temperature at which must be corrected the retort temperature after the deviation $\mathrm{i}$, is:

$T R T_{H i}=\operatorname{Min}\left\{\operatorname{TRT} / F_{p} \geq F_{o b j} \wedge t_{p}{ }^{\prime}=t_{p}\right\}$

If $\mathrm{TRT}_{\mathrm{Hi}}$ surpasses the practical limit, then:

If $T R T_{H i}>T R T_{\max } \Rightarrow T R T_{H i}=T R T_{\text {max }} \wedge t_{p}{ }^{\prime}=\operatorname{Min}\left\{t_{p} / F_{p} \geq F_{o b j}\right\}$

This higher temperature, $\mathrm{TRT}_{\mathrm{H}}$, needs to be calculated using a look-up table or curve on a graph showing alternative retort temperature-time combinations that were predetermined to deliver the same target lethality (iso-lethality curves) for each product. Mathematically, this equivalent process time can be calculated from the anatomy of the recovered process deviation and original process conditions as follows:

$t_{H}=\frac{t_{T R T}^{2}}{t_{L D T}}$

Equation 12 can be obtained as follows: consider a process in which two deviations occur in sequence. The normal retort temperature is TRT, the first deviation occurs over a time interval $\Delta \mathrm{t}$ at lower than normal retort temperature $\mathrm{TRT}_{\mathrm{D}}$ and the second occurs later over an equal time interval $\Delta \mathrm{t}$ at a higher than normal retort temperature $\mathrm{TRT}_{\mathrm{H}}$. If a "proportional corrected process" is applied to each one of the deviations as described in the previous tasks, the mathematical expressions for each correction will be as follows:

Correction $1=\frac{t_{T R T}-t_{H}}{t_{T R T}} \Delta t$

Correction $2=\frac{t_{L D T}-t_{T R T}}{t_{L D T}} \Delta t$

If we supposed now that $\mathrm{TRT}_{\mathrm{H}}$ is selected so both corrections are equivalent, we can equate both terms:

$$
\begin{aligned}
& \frac{t_{T R T}-t_{H}}{t_{T R T}} \Delta t=\frac{t_{L D T}-t_{T R T}}{t_{L D T}} \Delta t \\
& \Rightarrow t_{H}=\frac{t_{T R T}{ }^{2}}{t_{L D T}}
\end{aligned}
$$

Equation (12) and equation (16) are identities. 


\section{Validation of Task 4.}

The utility of this approach to on-line correction of process deviations was demonstrated experimentally as a means of preliminary validation. Cylindrical cans $(0.075 \mathrm{~m}$ diameter, $0.113 \mathrm{~m}$ height) containing a commercially prepared food product (Centauri Ravioli, 350g) were thermally processed in a vertical still-cook retort under saturated steam with maximum working pressure of 40 psig at $140^{\circ} \mathrm{C}$ (Loveless, Model 177). Both retort temperature and internal product cold spot temperature were monitored with K-type thermocouples, and recorded with an Omega 220 data logger and modem with COM1 connection port. Cans were processed under different combinations of retort temperature and process time, with the temperatures recorded every 2 seconds. Each normal process was defined with a come-up-time (CUT) of 7 minutes, during which the retort temperature increased linearly, followed by a period of constant retort temperature and a cooling cycle. Deviations during the process were deliberately perpetrated by manually shutting off the steam supply to the retort control system. Experiments were carried out in the Food Laboratory pilot plant of the Universidad Técnica Federico Santa Maria in Valparaiso, Chile.

\section{RESULTS AND DISCUSSIONS Equivalent Lethality Curves}

Look-up tables are used to find the alternative process time for the corrected process, and can be presented graphically as "equivalent process lethality curves" for each scheduled product/process. Therefore, equivalent process lethality curves were constructed for each of the two simulated products used in this study, and are shown in Figures 1 and 2 for the case of solid (pure conduction) and liquid (forced convection), respectively.

\section{Performance Demonstration}

Figures 3-6 show results from the four product/process simulations carried out to demonstrate the performance of these strategies. The figures contain retort temperature profiles resulting from on-line correction of process deviations happening at different times during the process (early and late) to both solid and liquid canned food products. Each figure shows the "normal" constant retort temperature profile expected for the originally scheduled process, along with the occurrence of a deviation (sudden step-drop in retort temperature for short duration) either relatively early or late into the process. In addition, for each deviation (one in each figure), three different alternative corrected process times are shown resulting from different strategies: "exact correction”, "proportional correction” and “commercial correction”.

In all cases, the extended process time required by the "commercial correction" strategy, is far in excess of the extended times called for by the other two strategies. Moreover, the new "proportional correction" strategy results in extending process time only slightly beyond that required for an "exact correction", and will always do so. These results are summarized in Table 3 , along with results from predicting the outcomes of each corrected process in terms of final process times required, and final lethality and quality retention achieved (using product/process data presented in Table 1). It is most interesting to note the dramatic improvement in nutrient (quality) retention between that resulting from the commercial correction (current industry practice) and that resulting from either of the other two strategies. 


\section{Demonstration of Safety Assurance by Complex Search Routine}

This on-line correction strategy was validated and tested for safety assurance by executing an exhaustive search routine with the use of the heat transfer models. Recall, the problem to be solved by the search routine was to determine if the minimum final lethality delivered by all the corrected processes that could be found among all the various types of deviations and process conditions considered in the problem domain met the criterion that it had to be greater than or equal to the lethality specified for the original scheduled process. Table 2 (presented earlier) identifies the problem domain by specifying the various types of deviations and process conditions that were explored and evaluated in the search routine. The search routine was designed to find a set of conditions under which the required search constraint was not met. No such conditions could be found.

\section{Correction strategy without extending process time and preliminary validation}

Using data from the constant-temperature heat penetration tests carried out in this study, an equivalent process lethality curve (for a target lethality of $\mathrm{F}_{\mathrm{o}}=6$ minutes) was constructed for the commercial ravioli product and can size used in this study, and is shown in Figure 7.

In order to validate the safety assurance of this new on-line control strategy, a number of heat penetration experiments were carried out in which process deviations were deliberately perpetrated by manual shut-off of the steam supply to the retort, causing the retort temperature and pressure to fall to a lower level for several minutes, after which the steam supply valve was reopened and the deviation quickly recovered. As soon as the complete anatomy of the deviation was known upon recovery, Equation (14) was used to calculate the high temperature equivalent process time $\left(t_{H i}\right)$, from which to obtain the higher retort temperature $\left(\mathrm{TRT}_{\mathrm{H}}\right)$ needed to accomplish the correction, using the iso-lethality curve in Figure 7. The retort controller set point was immediately adjusted upward to the correction temperature $\left(\mathrm{TRT}_{\mathrm{H}}\right)$, and brought back down to the originally scheduled retort temperature after an elapsed time equal to the duration of the initial perpetrated deviation. The process was then allowed to proceed normally for the duration of the remaining originally scheduled process time. During each test, retort and internal product cold spot temperatures were continually measured and recorded, and accumulated lethality was calculated as a function of cold spot temperature over time using the General method (assuming a z-value of $10 \mathrm{C}$ ). Results from a typical test run are presented in Figure 8, with the process conditions and parameters used for the test listed in Table 4.

Both temperature and lethality are shown as functions of time on Figure 8, with the temperature scale shown along the left side vertical axis, and the lethality scale shown along the right side vertical axis. In the case of this test, the target value for process lethality was 8 minutes and the normal scheduled retort temperature was intended to be $125^{\circ} \mathrm{C}$ for a scheduled process time of 61 minutes. The perpetrated deviation was initiated after approximately 45 minutes into the process, and held for 5.5 minutes, during which time the retort temperature fell to $122 \mathrm{C}$. Upon recovery from the deviation, the retort temperature was elevated to approximately $128{ }^{\circ} \mathrm{C}$ (determined from the calculation procedure described above) for five more minutes, and returned to the originally scheduled $125 \mathrm{C}$ for the remainder of the scheduled 61-minute process time.

The measured retort temperature profile (TRT) can be seen in Figure 8, clearly revealing the profile of the perpetrated deviation immediately followed by the high temperature correction process and return to normal, with the cooling cycle beginning right on schedule at the originally appointed process time of 61 minutes. The measured internal product cold spot temperature curve 
(Tcp) in Figure 8 reflects the expected erratic response to the combined deviation and correction perturbations experienced by the dynamic retort temperature. Most importantly, in spite of the erratic profile of the internal product cold spot temperature, the final accumulated lethality, calculated as a function of this profile by the General Method, still reached the target value of 8 minutes specified for the process.

\section{CONCLUSIONS}

This paper has described a practical and efficient strategy for on-line correction of thermal process deviations during retort sterilization of canned foods. This strategy takes into account the duration of the deviation in addition to the magnitude of the temperature drop. It calculates a "proportional" extended process time at the recovered retort temperature that will deliver the final specified target lethality with very little over processing in comparison to current industry practice. In addition, it is described a strategy that can assure thermal sterilization during unexpected process deviations without extending scheduled process time, and with an absolute minimum of over-processing. They are applicable to all types of foods or containers (solids, liquids, mixtures) or mechanisms of heat transfer (conduction, convection, both combined)

Results from an exhaustive search routine using the complex method support the logic and rationale behind the strategy by showing that the proposed strategy will always result in a corrected process that delivers no less than the final target lethality specified for the originally scheduled process. Economic impact of adopting this strategy over that currently used in industry practice can be a significant increase in production capacity for a typical cannery. In addition, utilizing this novel strategy canned products will attain a much higher quality.

\section{REFERENCES}

Akterian, S.G. (1996). Studying and controlling thermal sterilization of convection-heated canned foods using functions of sensitivity. Journal of Food Engineering, 29: 329-338.

Akterian, S.G. (1999). On-line control strategy for compensating for arbitrary deviations in heating medium temperature during batch thermal sterilization processes. Journal of Food Engineering, 39: 1-7.

Ball, C.O. 1928. Mathematical solution of problems on thermal processing of canned food. Univ. Cal. Pub. In Pub. Health 1, N 2, 15-245.

Bigelow, W.D., Bohart, G.S., Richardson, A.C. and Ball, C.O. 1920. Heat penetration in processing canned foods. Bull. No. 16-L Res. Lab. Natl. Canners Assn., Washington, D.C.

Datta, A.K., A.A. Teixeira, and J.E. Manson. Computer-based retort control logic for on-line correction of process deviations. J. Food Sci. 1986. 51(2): 480-483, 507.

Holdsworth, S.D. 1997. Thermal processing of packaged foods. Blackie Academic \& Professional. London.

Larkin. 2002. Personal Communication. Branch Chief, National Center for Food Safety and Technology, Food and Drug Administration (FDA/NCFST), Chicago, IL., USA.

Manson, J.E., Zahradnik, J.W., and Stumbo, C.R. 1970. Evaluation of lethality and nutrient retentions of conduction-heating food in rectangular containers. Food Technol. 24(11): 12971301.

Manson, J.E., Zahradnik, J.W., and Stumbo, C.R. 1974. Evaluation of thermal processes for conduction heating foods in pear-shaped containers. J. Food Sci., 39, 276-281.

Simpson, R., Aris, I., and Torres, J.A. 1989. Sterilization of conduction-heated foods in ovalshaped containers. J. Food Sci., 54(5), 1327-1331, 1363. 
Pham, Q. T. 1987. Calculation of thermal process lethality for conduction-heated canned foods. J. Food Sci., 52(4), 967-974.

Simpson, R. 2004. Control logic for on-line correction of batch sterilization processes applicable to any kind of canned food. Symposium of Thermal processing in the 21st century: Engineering modeling and automation, at IFT Meeting, 2004, Las Vegas, NV, USA

Stumbo, C.R. 1973. Thermobacteriology in food processing. 2nd ed. Academic Press, New York.

Teixeira, A., Dixon, J., Zahradnik, J. and Zinsmeiter, G. 1969. Computer optimization of nutrient retention in the thermal processing of conduction-heated foods. Food Technol. 23 (6): 845-850.

Teixeira, A.A. and Manson. J.E. (1982). Computer control of batch retort operations with online correction of process deviations. Food Technol. 36(4): 85-90.

Teixeira, A.A. 1992. Thermal process calculations, Chapter 11 in Handbook of Food Engineering, D.R. Heldman and D.B. Lund (eds.). Marcel Dekker, Inc. New York, pp. 563-619.

Teixeira, A.A. and Tucker, G.S. (1997). On-line retort control in thermal sterilization of canned foods. Food Control. 8(1): 13-20.

Teixeira, A.A., Balaban, M.O., Germer, S.P.M., Sadahira, M.S., Teixeira-Neto, R.O., and Vitali, A.A. (1999). Heat transfer model performance in simulating process deviations. Journal of Food Science, 64 (3): 488-493.

\section{ACKNOWLEDGEMENTS}

We kindly appreciate the contribution made by Mrs. Karin von Oetinger and Mr. Fernando Arcos. We also thank the Universidad Técnica Federico Santa María and University of Florida's Institute of Food and Agricultural Sciences and the Florida Experiment Station for contributing support to this work. Author Ricardo Simpson is grateful for the financial support provided by CONICYT through the FONDECYT project number 1050810.

\section{LIST OF TABLES}

Table 1. Product and process conditions used for on-line correction strategy simulations.

Table 2. Problem domain for search routine

Table 3. Outcomes of each corrected process deviation described in Figures 3-6 in terms of final process time, lethality and quality retention for the three different alternative correction methods.

Table 4. Process conditions and parameters used for heat penetration test with ravioli packed in cylindrical cans $(0.075 \mathrm{~m}$ diameter, $0.113 \mathrm{~m}$ height) producing results shown in Figure 8. 
Table 1. Product and process conditions used for on-line correction strategy simulations.

\begin{tabular}{|l|ccc|cc|cc|}
\hline \multirow{2}{*}{ Product Simulated } & \multicolumn{3}{|c|}{ Dimensions (cm) } & \multicolumn{2}{c|}{ Properties } & \multicolumn{2}{c|}{ Normal Process } \\
& Major & Intermedium & Minor & alfa $\left(\mathrm{m}^{2} / \mathrm{s}\right)$ & $\mathrm{f}_{\mathrm{h}}(\mathrm{min})$ & time $(\mathrm{min})$ & $\mathrm{TRT}\left({ }^{\circ} \mathrm{C}\right)$ \\
\hline $\begin{array}{l}\text { Pure Conduction Can, } \\
\text { Biot }>40\end{array}$ & 11.3 & - & 7.3 & $1.70 \mathrm{E}-07$ & 44.4 & 64.1 & 120 \\
\hline $\begin{array}{l}\text { Forced Convection Can, } \\
\text { Biot }<1\end{array}$ & 11.3 & - & 7.3 & - & 4.4 & 15.6 & 120 \\
\hline
\end{tabular}

Table 2. Problem domain for search routine

\begin{tabular}{|l|l|l|l|}
\hline $\begin{array}{l}\text { Process } \\
\text { Variable }\end{array}$ & $\begin{array}{l}\text { Description of } \\
\text { Process Variable }\end{array}$ & $\begin{array}{l}\text { Minimum } \\
\text { Value }\end{array}$ & $\begin{array}{l}\text { Maximum } \\
\text { Value }\end{array}$ \\
\hline $\mathrm{TRT}$ & $\begin{array}{l}\text { Scheduled Retort } \\
\text { Temperature }\end{array}$ & $110^{\circ} \mathrm{C}$ & $135^{\circ} \mathrm{C}$ \\
\hline $\mathrm{TRT}_{\mathrm{i}}$ & $\begin{array}{l}\text { Lowest retort temperature } \\
\text { reached during deviation } \mathrm{i}\end{array}$ & $100{ }^{\circ} \mathrm{C}$ & $\mathrm{TRT}-0.5^{\circ} \mathrm{C}$ \\
\hline $\mathrm{t}_{\mathrm{CUT}}$ & $\begin{array}{l}\text { Initial come up time of retort } \\
\text { to reach TRT. }\end{array}$ & $5[\mathrm{~min}]$ & $15[\mathrm{~min}]$ \\
\hline $\mathrm{t}_{\mathrm{dev}-\mathrm{i}}$ & $\begin{array}{l}\text { Time during the process at } \\
\text { which the deviation i begins. }\end{array}$ & $\mathrm{t}_{\mathrm{cut}}$ & $\mathrm{t}_{\mathrm{TRT}}$ \\
\hline $\mathrm{t}_{\mathrm{i}}$ & $\begin{array}{l}\text { Time duration of the } \\
\text { deviation i }\end{array}$ & $0.5[\mathrm{~min}]$ & $\mathrm{t}_{\mathrm{TRT}}-\mathrm{t}_{\mathrm{dev}-\mathrm{i}}$ \\
\hline $\mathrm{T}_{\text {ini }}$ & Initial product temperature. & $20^{\circ} \mathrm{C}$ & $70^{\circ} \mathrm{C}$ \\
\hline
\end{tabular}

Table 3. Outcomes of each corrected process deviation described in Figures 3-6 in terms of final process time, lethality and quality retention for the three different alternative correction methods.

\begin{tabular}{|l|c|c|c|c|c|c|}
\hline \multirow{2}{*}{} & \multicolumn{2}{|c|}{ EARLY DEVIATION } & \multicolumn{3}{c|}{ LATE DEVIATION } \\
\cline { 2 - 7 } & time (min) & Fo (min) & Nutrient Retention & time (min) & Fo (min) & Nutrient Retention \\
\hline PURE CONDUCTION & 64.1 & 6.0 & $72.7 \%$ & 64.1 & 6.0 & $72.7 \%$ \\
\hline Scheduled Process & 66.3 & 6.0 & $72.9 \%$ & 66.8 & 6.0 & $72.7 \%$ \\
Exact Correction & 67.5 & 6.5 & $72.2 \%$ & 67.5 & 6.2 & $72.3 \%$ \\
Proportional Correction & 86.2 & 16.3 & $62.3 \%$ & 86.2 & 14.4 & $62.8 \%$ \\
Comercial Correction & \multicolumn{7}{|c|}{} & & $92.4 \%$ \\
\hline FORCED CONVECTION & 15.6 & 6.0 & $92.4 \%$ & 15.6 & 6.0 & $90.9 \%$ \\
\hline Scheduled Process & 18.4 & 6.1 & $91.5 \%$ & 19.6 & 6.0 & $89.9 \%$ \\
Exact Correction & 20.8 & 8.0 & $89.7 \%$ & 20.8 & 7.0 & $82.8 \%$ \\
Proportional Correction & 25.6 & 11.8 & $86.2 \%$ & 30.6 & 14.7 & \\
Comercial Correction & \multicolumn{7}{|c|}{}
\end{tabular}


Table 4. Process conditions and parameters used for heat penetration test with ravioli packed in cylindrical cans $(0.075 \mathrm{~m}$ diameter, $0.113 \mathrm{~m}$ height) producing results shown in Figure 8.

\begin{tabular}{|l|c|}
\hline Process Parameters (units) & Value chosen for heat penetration test \\
\hline Reference Temperature $\left({ }^{\circ} \mathrm{C}\right)$ & 121.1 \\
\hline Scheduled process time $(\mathrm{min})$ & 61 \\
\hline Low temperature at deviation $\left({ }^{\circ} \mathrm{C}\right)$ & 122 \\
\hline Initial internal product temperature $\left({ }^{\circ} \mathrm{C}\right)$ & 19 \\
\hline Time duration of deviation, $\Delta,(\mathrm{min})$ & 5.5 \\
\hline Target process lethality, Fo, $(\mathrm{min})$ & 8 \\
\hline Microbial temperature factor, $\mathrm{z},\left({ }^{\circ} \mathrm{C}\right)$ & 10 \\
\hline Scheduled retort temperature $\left({ }^{\circ} \mathrm{C}\right)$ & 125 \\
\hline
\end{tabular}

\section{LIST OF FIGURES}

Figure 1. Equivalent process lethality curve for simulated solid product under pure conduction heating, showing retort temperature / process time combinations that deliver the same final target lethality.

Figure 2. Equivalent process lethality curve for simulated liquid product under forced convection heating, showing retort temperature / process time combinations that deliver the same final target lethality.

Figure 3. Pure conduction simulation for on-line correction of an unexpected retort temperature deviation occurring early into the scheduled process for a cylindrical can of solid food under still cook.

Figure 4. Pure conduction simulation for on-line correction of an unexpected retort temperature deviation occurring late into the scheduled process for a cylindrical can of solid food under still cook.

Figure 5. Forced convection simulation for on-line correction of an unexpected retort temperature deviation occurring early into the scheduled process for a cylindrical can of liquid food under agitated cook.

Figure 6. Forced convection simulation for on-line correction of an unexpected retort temperature deviation occurring late into the scheduled process for a cylindrical can of liquid food under agitated cook.

Figure 7. Iso-lethality curve showing equivalent combinations of process time and retort temperature that achieve the same process lethality $\left(F_{o}=6 \mathrm{~min}\right)$ for ravioli packed in cylindrical cans (0.075m diameter, $0.113 \mathrm{~m}$ height).

Figure 8. Profiles of retort (TRT) and internal product cold spot temperatures (Tcp) over time (scale on left), along with profile of accumulated lethality over time (scale on right) from heat penetration test with ravioli in cans $(0.075 \mathrm{~m}$ diameter, $0.113 \mathrm{~m}$ height) experiencing perpetrated process deviation immediately followed by temporary high retort temperature correction (calculated on-line). 
Figure 1. Equivalent process lethality curve for simulated solid product under pure conduction heating, showing retort temperature / process time combinations that deliver the same final target lethality.

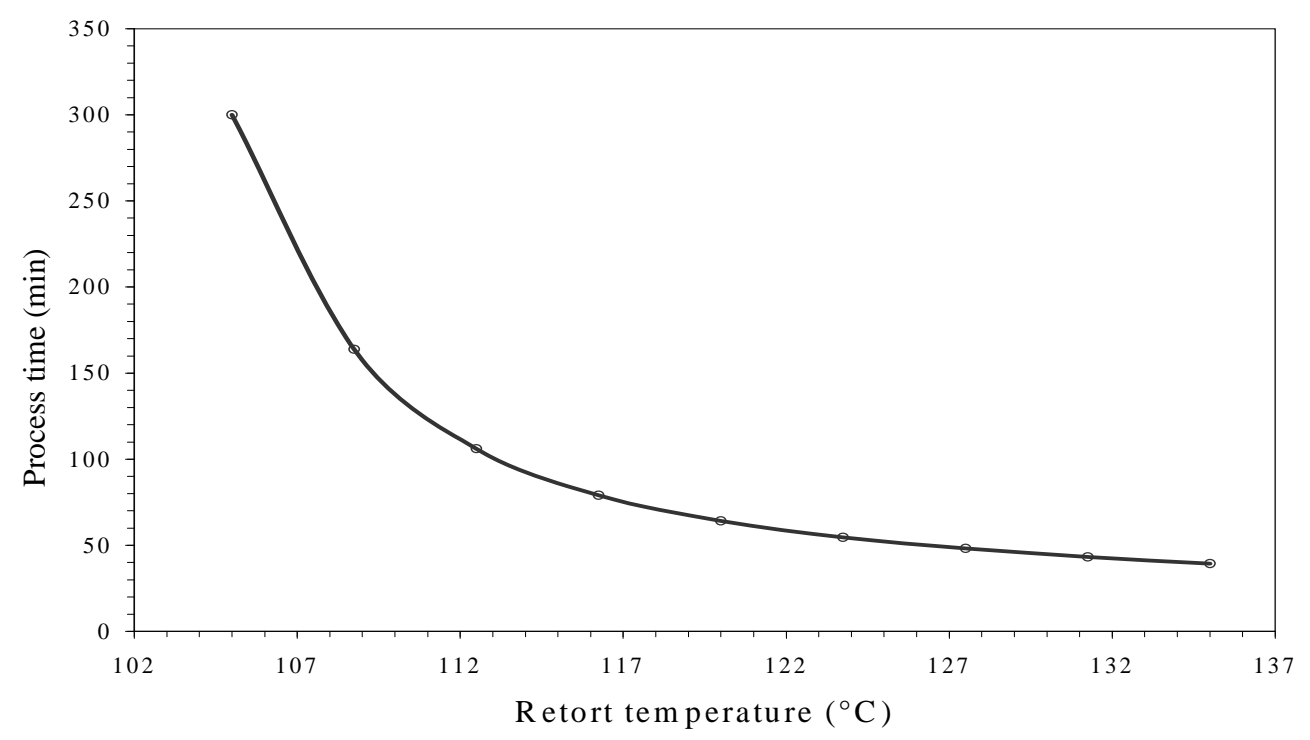

Figure 2. Equivalent process lethality curve for simulated liquid product under forced convection heating, showing retort temperature / process time combinations that deliver the same final target lethality.

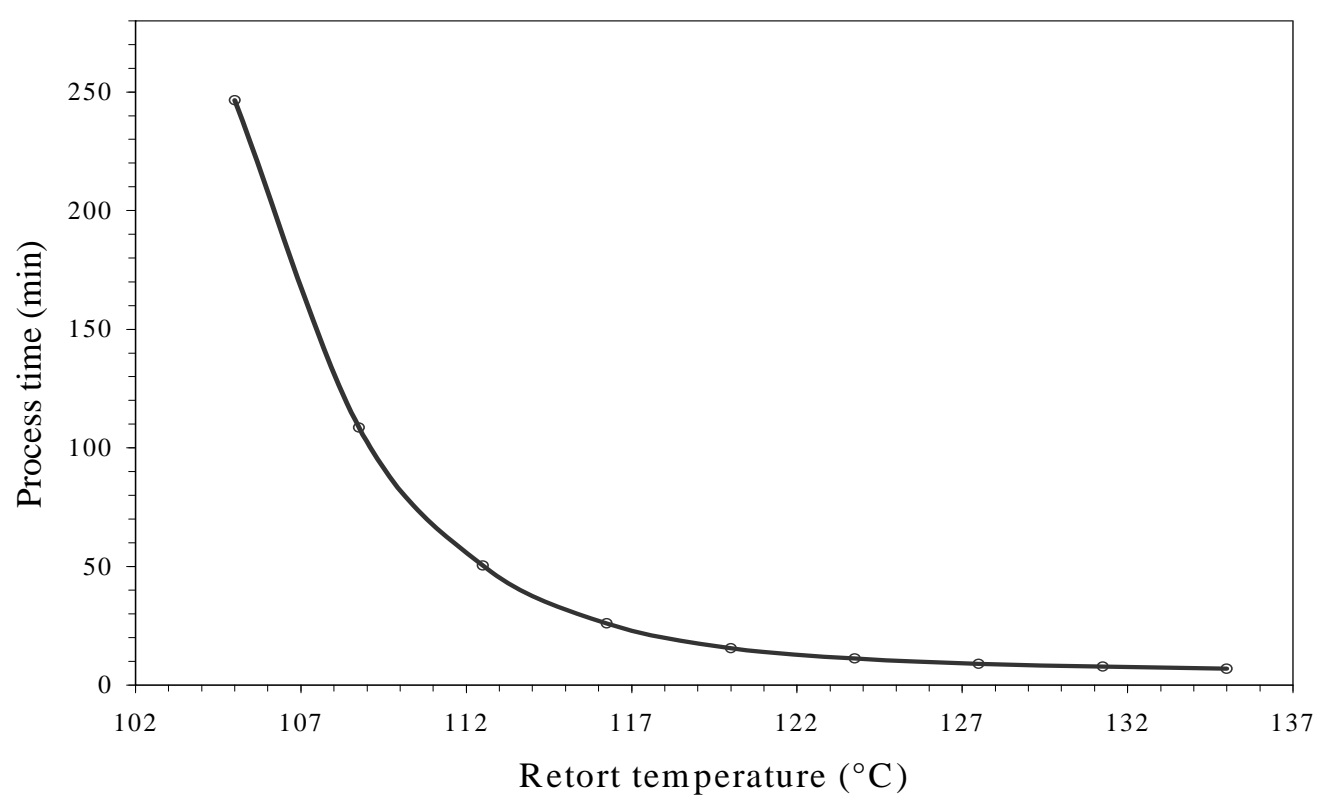


Figure 3. Pure conduction simulation for on-line correction of an unexpected retort temperature deviation occurring early into the scheduled process for a cylindrical can of solid food under still cook.

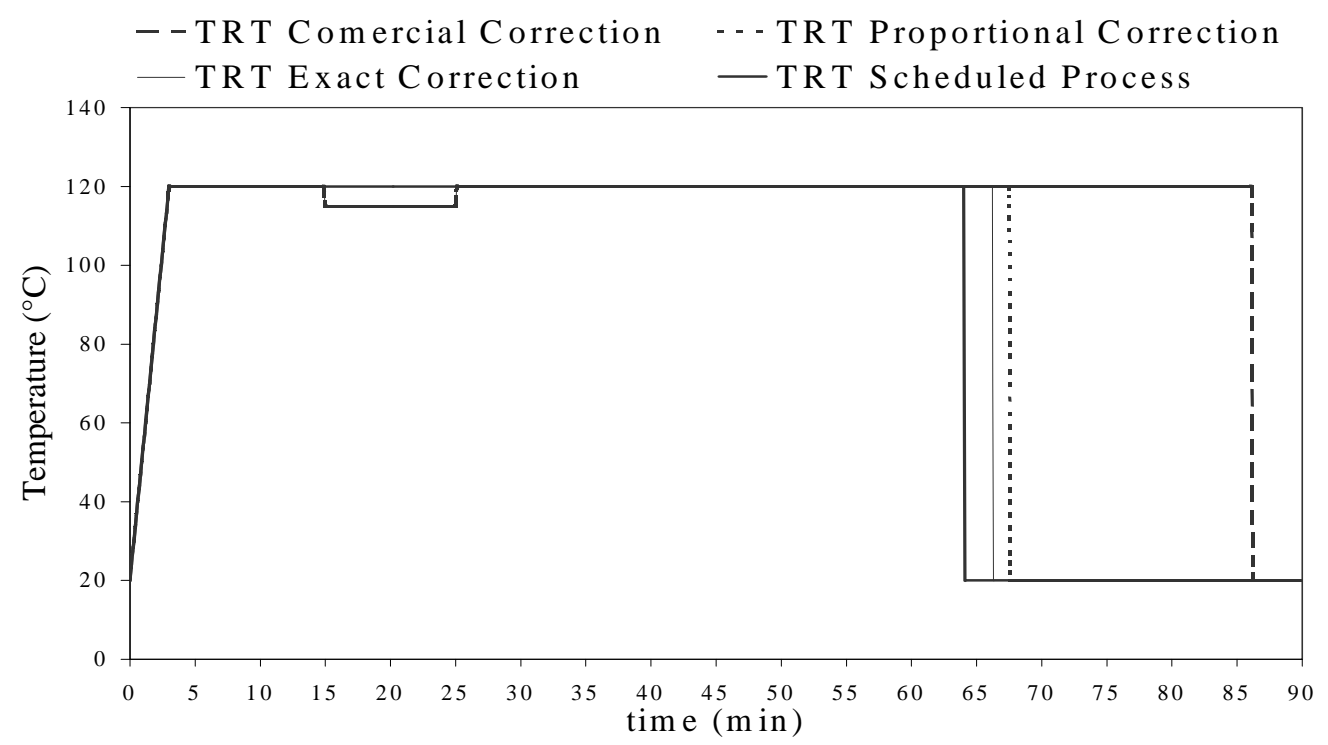

Figure 4. Pure conduction simulation for on-line correction of an unexpected retort temperature deviation occurring late into the scheduled process for a cylindrical can of solid food under still cook.

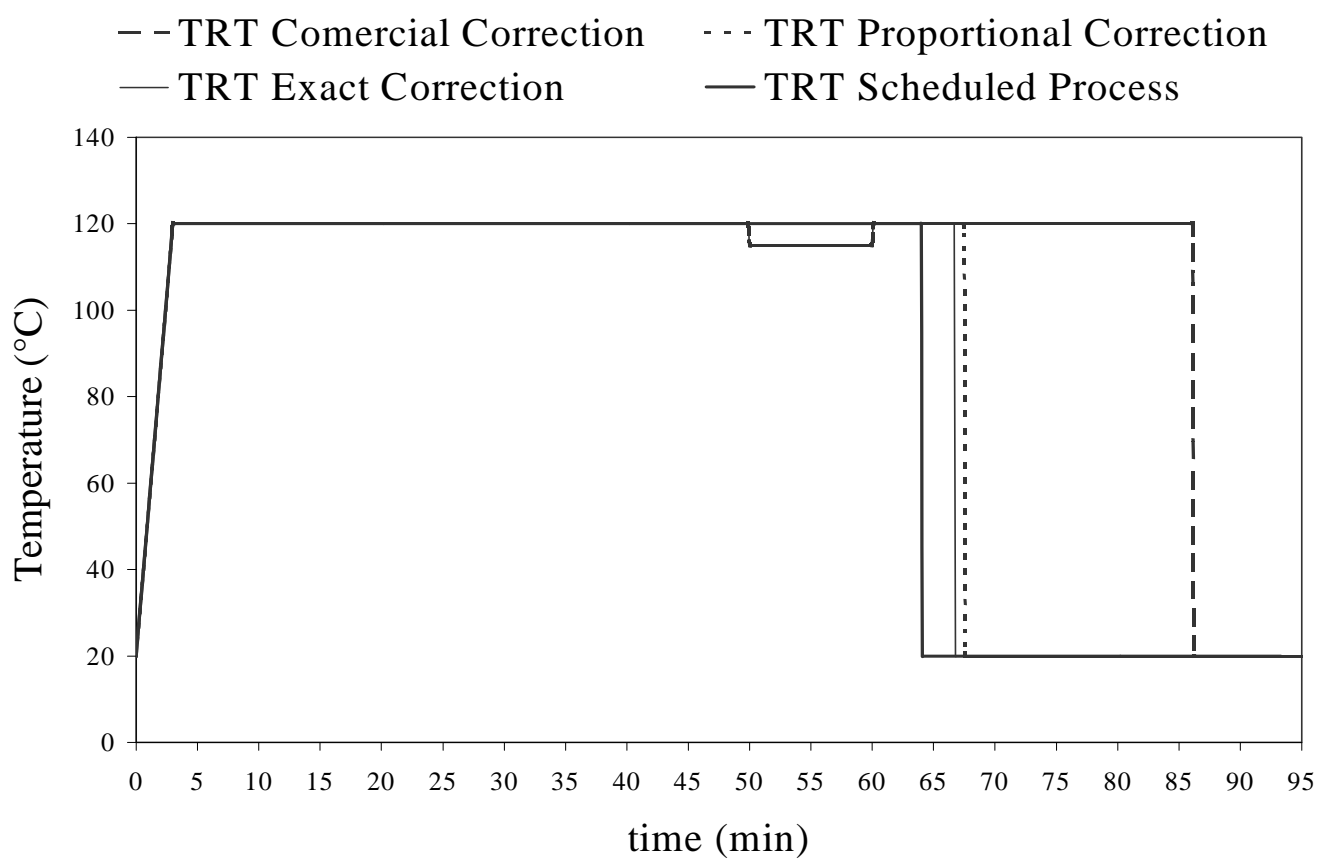


Figure 5. Forced convection simulation for on-line correction of an unexpected retort temperature deviation occurring early into the scheduled process for a cylindrical can of liquid food under agitated cook.

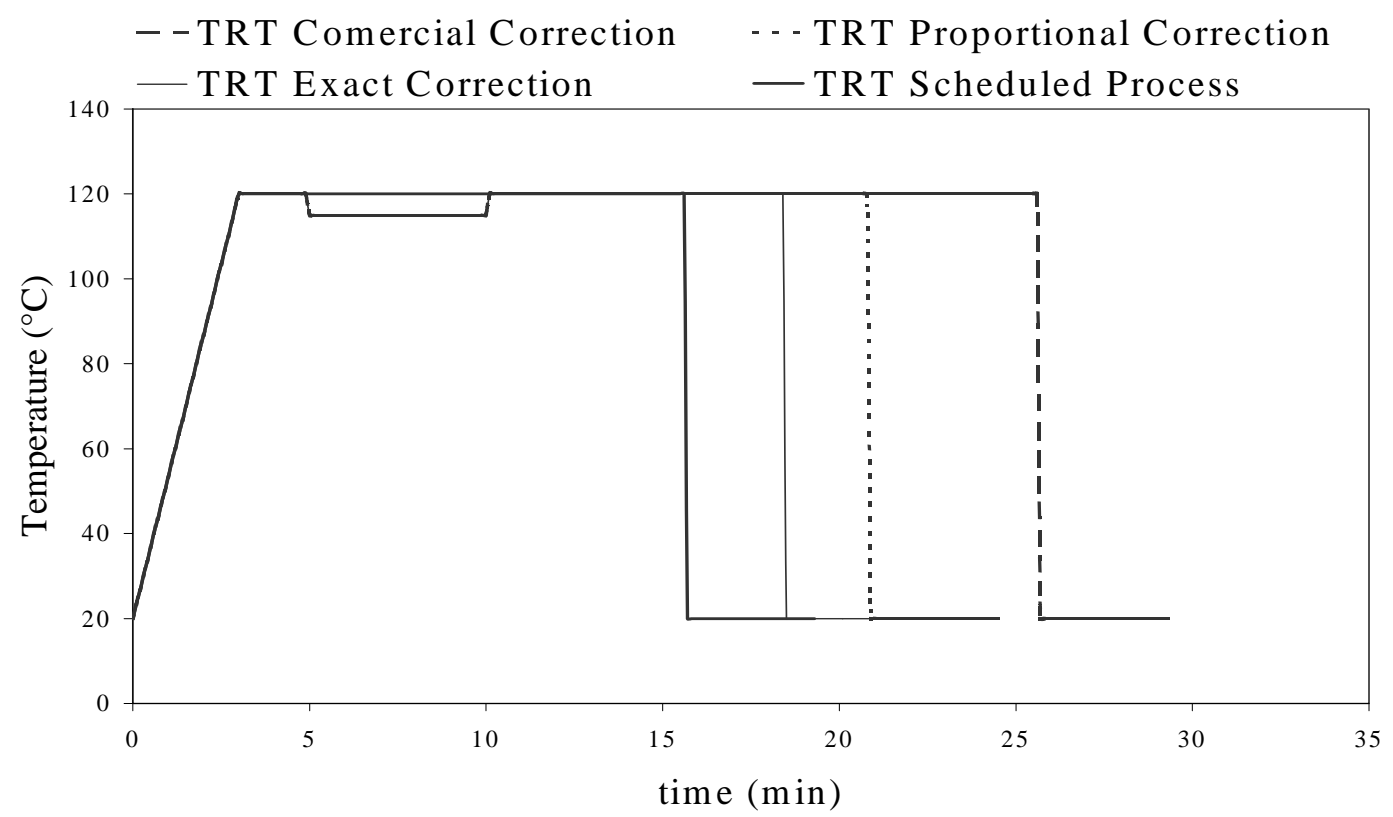

Figure 6. Forced convection simulation for on-line correction of an unexpected retort temperature deviation occurring late into the scheduled process for a cylindrical can of liquid food under agitated cook.
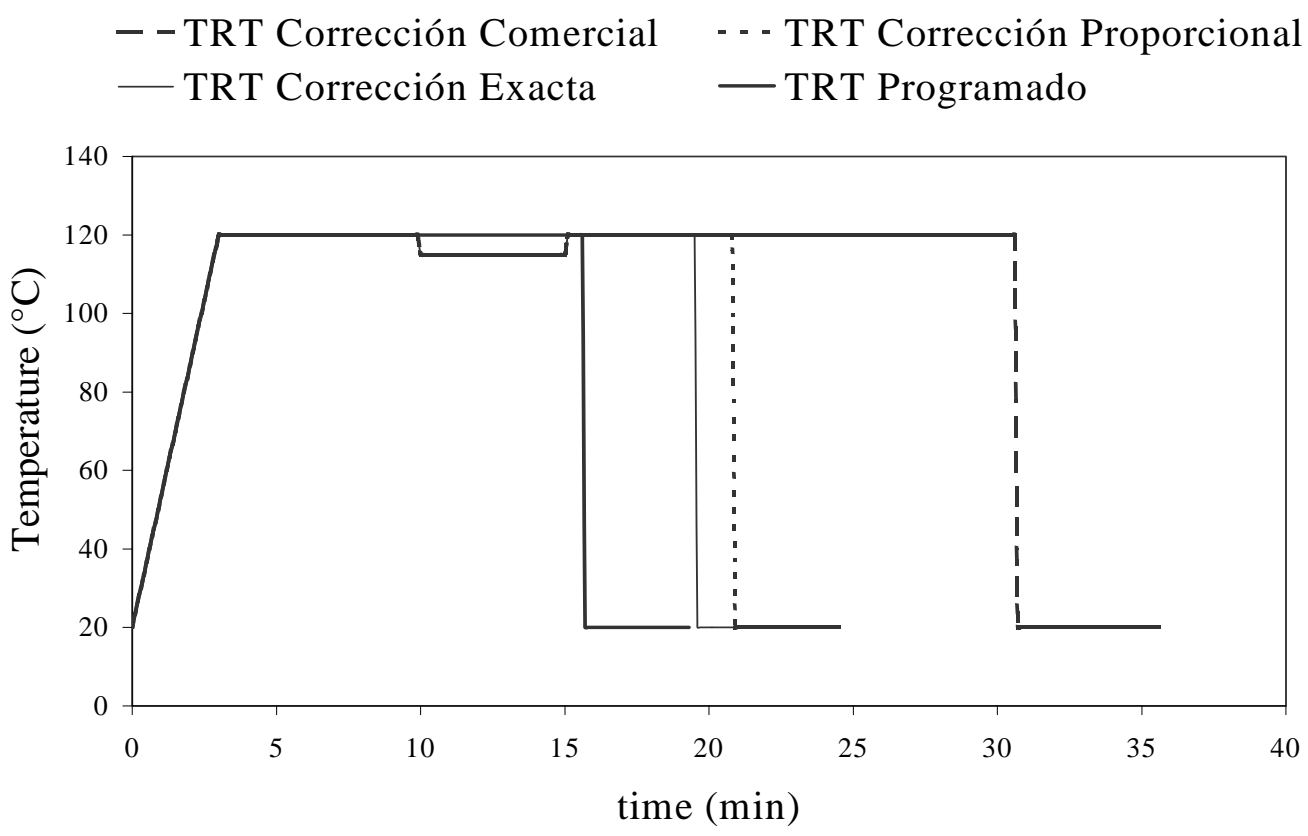
Figure 7. Iso-lethality curve showing equivalent combinations of process time and retort temperature that achieve the same process lethality $\left(F_{o}=6 \mathrm{~min}\right)$ for ravioli packed in cylindrical cans $(0.075 \mathrm{~m}$ diameter, $0.113 \mathrm{~m}$ height).

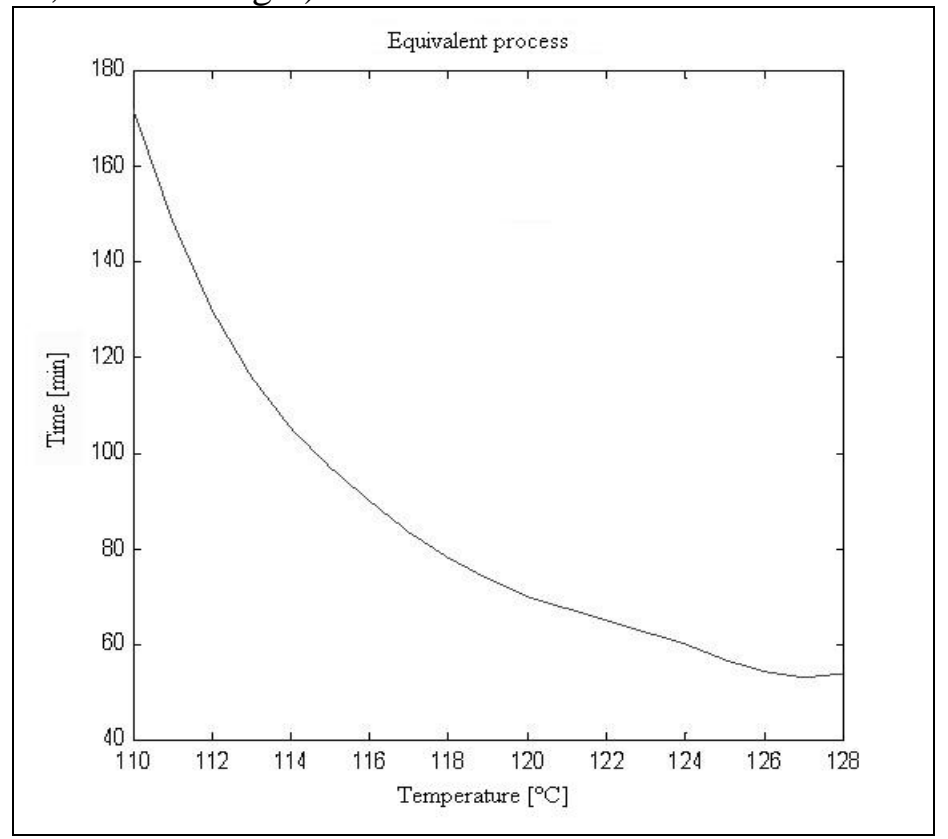

Figure 8. Profiles of retort (TRT) and internal product cold spot temperatures (Tcp) over time (scale on left), along with profile of accumulated lethality over time (scale on right) from heat penetration test with ravioli in cans $(0.075 \mathrm{~m}$ diameter, $0.113 \mathrm{~m}$ height) experiencing perpetrated process deviation immediately followed by temporary high retort temperature correction (calculated on-line).

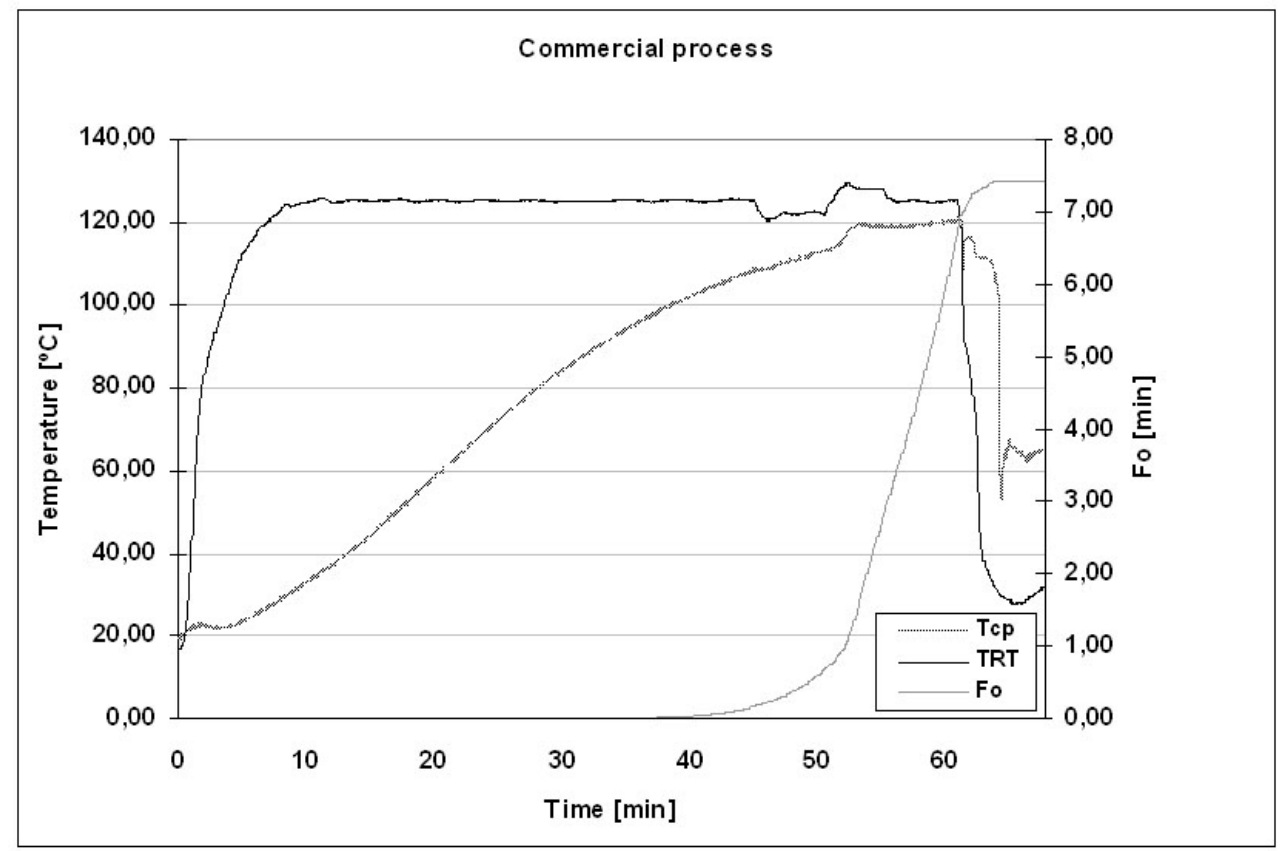




\section{NOMENCLATURE}

\begin{tabular}{|c|c|}
\hline$A$ & : Heat transfer area \\
\hline$C p$ & : Heat capacity \\
\hline$F_{o b j}$ & : F-value established for the schedule process \\
\hline$F_{p}$ & : F-value for the process with corrected deviations \\
\hline$F_{\text {proportional }}$ & : F-value with the proportional correction \\
\hline$F_{T O L}$ & : F-value specified for normal scheduled process \\
\hline$h$ & : Vertical distance \\
\hline$H$ & : Operating time of the plant during the season (h) \\
\hline$n$ & : Number of deviations occurring during the process \\
\hline$N_{B i}$ & : Number of batches processed per retort $\mathbf{i}$ during the season \\
\hline$r$ & : Radial distance \\
\hline$t$ & : Time \\
\hline$t_{c i}$ & : Time to load retort $\mathbf{i}$ with product $\mathbf{j}$ (h) \\
\hline$t_{d i}$ & : Time to download retort $\mathbf{i}$ with product $\mathbf{j}$ (h) \\
\hline$t_{D}$ & : Corrected process time \\
\hline$t_{D \text { commercial }}$ & : Corrected process time for commercial strategy \\
\hline$t_{D i}$ & : Process time at the deviation temperature $T R T_{i}$ \\
\hline$t_{D \text { proportional }}$ & : Corrected process time for proportional strategy \\
\hline$t_{H}$ & : Equivalent process time at required higher temperature \\
\hline$t_{L D T}$ & : Equivalent process time at the lower deviation temperature \\
\hline$t_{o j}$ & : Time to operate retort $\mathbf{i}$ (process cycle time) with product $\mathbf{j}$ (h) \\
\hline$t_{p}$ & : Process time \\
\hline$t_{T R T}$ & : Pre-established process time at retort temperature $T R T$ \\
\hline$T$ & : Temperature \\
\hline$T c p$ & : Temperature in the coldest point \\
\hline$T_{\text {ref }}$ & : Reference temperature for microbial lethality \\
\hline$T R T$ & : Retort temperature \\
\hline $\begin{array}{l}T R T_{H} \\
\text { deviation i }\end{array}$ & : Lowest temperature at which must be reestablished process temperature after \\
\hline$T R T_{i}$ & : Lowest temperature during the deviation $\mathrm{i}$ \\
\hline$T R T_{\max }$ & : Temperature than cannot be surpassed (practical limit) \\
\hline$U$ & : Universe of feasible process conditions in search routine \\
\hline$U_{h t}$ & : Global heat transfer coefficient \\
\hline Vol & : Volume of can \\
\hline$z$ & : Temperature change necessary to alter the TDT by one log-cycle \\
\hline$\Delta t$ & : Duration time of the process deviation \\
\hline$\Delta t_{i}$ & : Duration of deviation i \\
\hline$\alpha$ & : Thermal diffusivity \\
\hline$\rho$ & : Liquid density \\
\hline
\end{tabular}

